\title{
O Apocalipse segundo o corvo
}

\section{The Apocalypse according to the crow}

\author{
Álvaro Cardoso Gomes \\ Universidade Santo Amaro, São Paulo, São Paulo / Brasil \\ alcgomes@uol.com.br
}

Resumo: Este artigo analisa o livro Relatos de um corvo sedutor, uma fábula de autoria de Péricles Prade. É nosso intento mostrar que o discurso feito pela ave torna-se a única realidade. Com toda sua incongruência, com todos os seus deslocamentos, com todas as suas implicações, ele remete a mitos arcaicos e modernos, de modo a criar um mundo que funciona de acordo com suas próprias leis e avesso à lógica cartesiana. O corvo, pássaro contraditório que reúne qualidades positivas e negativas, seja ele entendido como prenunciador da morte ou como enunciador de novos tempos, será visto simbolicamente como um demiurgo, um criador de mundos por haver, igualando-se, nesse sentido, aos poetas e aos artistas de modo geral.

Palavras-chave: corvo; mitos; Apocalipse, Péricles Prade.

Abstract: This article analyzes the book Relatos de um corvo sedutor, a fable written by Pericles Prade. It is our intent to show that the speech made by the bird becomes the only reality. With all its incongruity, with all its displacements, with all its implications, it refers to archaic and modern myths, in order to create a world that works according to its own laws and opposes the Cartesian logic. The crow, a contradictory bird gathering positive and negative qualities, whether it is believed to be a precursor of death or an enunciator of new times, will be symbolically seen here as a demiurge, a creator of worlds to be, thus equating with poets and artists in general.

Keywords: crow; myths; Apocalypse, Péricles Prade. 
Relatos de um corvo sedutor é um conjunto de dez narrativas, escritas por Péricles Prade, de cunho fantástico e/ou maravilhoso, precedidas de um texto introdutório, intitulado "Anunciação", em que se apresenta o narrador - um corvo, "o de bico mais saliente", que voa entre corvos. A partir de sua apresentação, esse corvo, possuidor de uma óptica privilegiada, porque vê as coisas do alto e constrói sua própria história, assume a voz narrativa e passa a contar os relatos em primeira pessoa, adotando um movimento pendular, ora se distanciado dos eventos, tornando-os quase neutros, ora interferindo no discurso, impregnando-o de subjetividade, para comentar os fatos e estabelecer, assim, cumplicidade com o leitor. Para exercer este seu mister, sobrevoa terras, registrando cenas, evocando seres históricos, ficcionais e míticos, até aportar na Ilha de Santa Catarina e/ou de Nossa Senhora do Desterro, onde a ação se desenrolará, para compor uma paródia, na linha do grotesco, do "Apocalipse" segundo o evangelho de João, que culmina com o Juízo Final no último relato, quando se dá a purgação dos pecados dos habitantes do espaço evocado.

Iniciamos nossa abordagem ao livro com um verbete sobre o nobre animal, narrador privilegiado, profeta e demiurgo: "O simbolismo do corvo [...] é cheio de contradições. Demiurgo e herói civilizador, clarividente e profeta, pássaro solar e tenebroso, ele anuncia a infelicidade, a morte e às vezes ele é protetor". ${ }^{1}$

Ao tratar do simbolismo da ave, os autores apontam-lhe a ambivalência, entrevista em alguns pares que, em realidade, remetem a um só, como se ele constituísse uma contradição em termos: é um pássaro solar e, ao mesmo tempo, um pássaro das trevas; é um herói civilizador e, ao mesmo tempo, anuncia a infelicidade, a morte; o negro de suas penas, se associado ao nada, ao fim dos tempos, também pode ser associado ao princípio, fons et origo.

A revitalização da imagem do corvo por parte de Prade está a serviço de uma amplificação do sentido ambíguo desse pássaro simbólico, o que serve para explicar - ou pelo menos complicar - o jogo labiríntico que os relatos oferecem e que fazem com que o leitor mergulhe de cabeça

\footnotetext{
1 "Le symbolisme du corbeau [...] est plein de contradictions. Démiurge et héros civilisateur, clairvoyant et prophète, oiseau solaire et ténébreux, il annonce le malheur et la mort et parfois il protège" (CHEVALIER; GHEERBRANT. Dictionnaire des symboles, p. 92, tradução nossa).
} 
num espaço onírico, para onde são convocados seres míticos, lendários, históricos e espaços dos mais diversos, que confluem para uma geografia única, que é a Ilha de Santa Catarina. É lá que acontece um Apocalipse, um Juízo Final que, de modo antifrásico, remete ao Gênesis, ou viceversa, como, aliás, enuncia o corvo nas últimas frases da narrativa: "e o fim, tenho a mais absoluta certeza, substituirá o começo, possibilitando o nascimento de outra narrativa exemplar no tempo dos aflitos". ${ }^{2}$

O corvo de Prade é um ser de grandeza ímpar, capaz de dominar a linguagem, em todas suas modulações, e, ao mesmo tempo, é capaz de projetar discursos, relatos - uma fábula - e, por conseguinte, é um demiurgo, um criador de mundos por haver, igualando-se, nesse sentido, aos aedos, aos poetas, aos artistas de modo geral. Contudo, não deixa de ser uma ave falante e, como tal, faz com que a ficção de Prade se insira num gênero literário muito específico e bastante tradicional, o daquele em que os animais falavam e/ou de animais que tinham comportamento humano. O corvo sedutor pertence, pois, a uma diferente estirpe de animais, e assim poder inventar um universo, para onde convergem seres históricos e seres imaginários.

Desse modo, ele se torna um ser diferenciado já desde a "Anunciação", quando é apresentado pelo narrador daquela primeira parte do livro, que o situa no início dos tempos, quando as "águas ainda eram ferventes". O corvo é descrito como sendo, entre seus iguais, "o de bico mais saliente, cujo nome não é Gabriel" e possuidor de "voz rouca cortada pelos ventos do Oriente". A sinédoque que lhe determina o ser - o "bico saliente" -, torna-se o seu sinal mais forte de identificação física e psíquica, remetendo à ideia de que ele tem uma especificidade em relação aos demais corvos, pois seu bico é o instrumento com que vai interferir no mundo. Seria algo equivalente ao nariz nos humanos - mas, em vez de "meter o nariz onde...", ele mete o bico. Já a referência ao nome Gabriel, mesmo que pela negativa, ainda remete ao clássico arcanjo anunciador, pois há aí uma litotes: "figura de linguagem próxima da ironia, consiste em afirmar o positivo pelo negativo, em sugerir o grau positivo de uma ideia pela negativa do contrário". ${ }^{3}$ Para corroborar essa ideia, lembramos que o primeiro capítulo do livro chama-se "Anunciação", além de que a "voz rouca" do corvo, como uma boa voz enunciadora, é cortada pelos

2 PRADE. Relatos de um corvo sedutor, p. 59.

${ }^{3}$ MOISÉS. Dicionário de termos literários, p. 270. 
ventos, que vêm do Oriente, de onde se origina tudo o que é primitivo - as lendas, os mitos fundadores.

Logo depois de apresentado, o corvo apodera-se da voz narrativa, para não mais abandoná-la, substituindo de vez o narrador inicial, que se torna mero adjuvante e, depois, desaparece para sempre. Utilizandose da primeira pessoa do discurso, o pássaro entra na ribalta: "Sou o filho ilegítimo do Revelado, o eterno número sete da tribo. Aqui deixo à posteridade os relatos do que aconteceu em apenas três dias de viagem". 4 Na breve biografia que faz de si, chama a atenção o fato de ser filho "ilegítimo" de uma espécie de Messias, o "Revelado" e de ser o "eterno número sete da tribo". Sua ilegitimidade, apesar do pai ilustre ou pelo fato de ter um pai ilustre, é que o caracteriza como autêntico outsider, o que o número especial a ele determinado só vem confirmar. Como se sabe, os números "não são meramente a expressão de quantidades, mas ideias-forças, cada um com sua própria característica" ${ }^{5}$ e, no caso, o número sete constitui-se num "símbolo da vida eterna. Ele simboliza um ciclo completo, uma perfeição dinâmica [...], símbolo de uma totalidade em movimento ou de um dinamismo total" ${ }^{.} \mathrm{O}$ fato de o corvo sofrer uma danação, ao ser designado para sempre como o número sete, o torna um ser privilegiado, pois tem como característica a "perfeição dinâmica e total", a "totalidade em movimento". Isso fica patente em seu périplo, por três dias, quando compõe delirantes relatos, nos quais atuam seres díspares, que se juntam, graças às aproximações propiciadas por um imaginário fundado no devaneio onírico-erótico.

$\mathrm{O}$ primeiro dos relatos empreendido pelo corvo intitula-se "As cidades visíveis sob o corpo voador" - nele, o pássaro negro viaja até o seu destino, a Ilha de Nossa Senhora do Desterro, a capital do estado de Santa Catarina, que, por injunções políticas, acabou por ter o nome substituído para Florianópolis. Há aqui um desejo de retorno do pássaro às origens históricas da cidade, que se acentua na referência às remanescentes igrejas do século XVIII. Esse desejo de retorno à imagem mais antiga da Ilha

\footnotetext{
${ }^{4}$ PRADE. Relatos de um corvo sedutor, p. 11.

5 "Are not merely the expressions of quantities, but idea-forces, each with a particular character of its own” (CIRLOT. A dictionary of symbols, p. 230, tradução nossa).

6 “symbole de vie éternelle. Il symbolise un cycle complet, une perfection dynamique [...], symbole d'une totalité en mouvement ou d'un dynamisme total" (CHEVALIER ET GHEERBRANT. Dictionnaire des symboles, p. 171-172, tradução nossa, grifos nossos).
} 
justifica-se pelo fato de ela ter um valor simbólico na narrativa. O périplo tem início com a aterrissagem do corvo na Ilha primordial, arquetípica, para cumprir seu "principal objetivo", qual seja o de convencer o pintor onírico-erótico Rodrigo Antônio de $\mathrm{Haro}^{7}$ a repintar as igrejas do século XVIII. Observa-se a partir daí um processo de "carnavalização", que se evidenciará em todos os relatos e será a marca registrada do modo muito específico como o corvo conduz a narrativa.

O termo "carnavalização" e o seu conceito foram criados e desenvolvidos por Bakhtin. Para o teórico russo,

é uma forma sincrética de espetáculo de caráter ritual, muito complexa, variada, que, sob base carnavalesca geral, apresenta diversos matizes e variações, dependendo da diferença de épocas, povos e festejos particulares. [...] a carnavalização ajudou constantemente a remover barreiras de toda espécie entre os gêneros, entre os sistemas herméticos de pensamentos, entre diferentes estilos, etc., destruindo toda hermeticidade e o desconhecimento mútuo, aproximando os elementos distantes e unificando os dispersos. ${ }^{8}$

Chama-nos a atenção, no texto de Bakhtin, a referência ao sincretismo, à remoção de barreira entre gêneros, estilos e aproximação de elementos distantes. Isso está bem patente no texto de Prade, na fusão de gêneros e estilos (o estilo moderno de Haro e o neoclássico das igrejas do século XVIII), em que o principal objetivo do corvo, anunciado por sua trombeta salvadora, é restituir à Ilha a sua feição original, mágica, antes de ser corrompida pelo viés político. A mistura de gêneros e estilos também comparece na construção do discurso empreendido pelo narrador, pois há fusão da poesia e da prosa, do estilo sublime e do estilo baixo e, sobretudo, no contraste entre a extrema transparência da linguagem e a complexidade das livres-associações das imagens. Chama a atenção igualmente, no processo de carnavalização, a aproximação de "elementos distantes", entrevista na espada-fálica de Floriano Peixoto e nas "chaves do Paraíso", mencionadas mais adiante. Entretanto, nesse caso, dá-se um processo de profanação, no castigo dos pecadores - o "pedófilo de batina" e o "outro pecador" - e no ato do corvo de atirar ao mar as

\footnotetext{
${ }^{7}$ Rodrigo Antônio de Haro (1939) é um poeta, mosaicista e artista multifacetado brasileiro.

${ }^{8}$ BAKHTIN. Problemas da poética de Dostoievski, p. 122 e 134, grifos do autor.
} 
"chaves do Paraíso", para poder começar a maior de suas aventuras. Ou seja: negando o Paraíso e profanando-o, a ave ingressa num mundo infernal, regido por suas próprias leis, de modo geral, as carnavalescas em que há "a quebra de todos os tabus e hierarquias, [...] a manifestação das mais diversas forças íntimas, primitivas, inconfessáveis do homem que não podem ser manifestadas e declaradas durante a vida cotidiana". 9

A maior das aventuras do corvo (que começa a partir do segundo relato), sob instigação da perda do Paraíso, tem como preâmbulo a revelação de que, antes de chegar à Ilha de Nossa Senhora do Desterro, ele havia sobrevoado alguns locais, enquanto, numa atitude escatológica e rabelaisiana, ia liberando fezes sobre eles: Florença, Paris, Salem, Tóquio, Buenos Aires, Dublin e Alexandria. Se, de um lado, o ato de defecar sugere simples profanação, por outro lado, pode sugerir também fecundação. As cidades, assim referidas pelo anjo anunciador, fecundamse, ganham vida, povoam-se de seres de primeira grandeza. Quatro dessas cidades são capitais e três, cidades especiais: Florença, pelas artes, Salem, pelo ocultismo e Alexandria, pela tradição livresca, cultural. Cada localidade dessas tem seu(s) habitante(s) emblemático(s): Gioconda, em Florença; Sartre, Simone de Beauvoir e Edith Piaf, em Paris; Nathaniel Hawthorne, em Salem; a enigmática Peônia, a "profetiza adúltera", em Tóquio; Borges, em Buenos Aires; James Joyce, em Dublin, e Kaváfis, em Alexandria, que desperta $(\mathrm{m})$ na ave alucinações das mais diversas, entre artísticas e eróticas. É possível ver aí, nessa conjugação de cidades das mais díspares, uma referência implícita aos quatro continentes Europa, América, Extremo Oriente e Oriente Próximo, como se tais localidades representassem uma súmula do mundo conhecido, visitado pelo aventureiro-corvo. Em realidade, a ave está chegando ao término de uma longa viagem e, como os antigos navegantes e conquistadores, aportará num simulacro das Ilhas Afortunadas, ${ }^{10}$ no caso, representado pela Ilha de Nossa Senhora do Desterro, que, por ser uma ilha, constitui um centro espiritual.

A partir do próximo capítulo, o corvo promete contar o "resto" de suas aventuras. Contudo, como se verificará no relato de número II - "Em forma de guitarra e antes do salto do lobo oculto" -, ele não

\footnotetext{
${ }^{9}$ BAKHTIN. Problemas da poética de Dostoievski, p. 42.

${ }^{10}$ É o que acontece, por exemplo, com Vasco da Gama e seus comandados que, ao fim da viagem às Índias, recebem como prêmio uma visita à Ilha dos Amores.
} 
passará de um observador/narrador privilegiado, pois desaparecerá de cena, comportando-se como um autêntico narrador onisciente. Quem assume a ribalta - personagem privilegiada - é o beatle John Lennon, reinando na praia de Campeche, sobre um trono em forma de guitarra. $\mathrm{O}$ fragmento, todo poético, sugere uma paisagem que lembra mais um cenário artificial. Ressalte-se também a imagem do mar, "lembrando vidro estilhaçado", e a referência ao inusitado "fogo branco", que contrasta com as sombras e, de modo paradoxal, emanam do pôr do sol. Tudo isso leva à criação de um espaço onírico, governado por um soberano, cujas qualidades se acentuam em sua generosidade e capacidade de dominar as forças benéficas da natureza e de disseminá-las, junto às ondas sonoras de sua música, para criar sensações sinestésicas.

O rei é, de modo geral, "conhecido como uma projeção de um eu superior, um ideal a realizar". ${ }^{11}$ Como tal, tem a função de "estabelecimento da justiça e da paz, quer dizer, do equilíbrio e da harmonia do mundo", ${ }^{12}$ como acontece com John Lennon neste trecho do relato. É por isso que são convocados, como se fossem seus cortesãos, animais heráldicos e emblemáticos, por seu caráter solar: um leão, um touro, um cão, uma águia. Tais animais têm esse valor energético contaminado por qualidades negativas: o leão é castrado e sua juba grisalha tem "odor de fêmea", o touro é manco, o cão persa tem "cara de homem malvado" e, por fim, a "águia revoltada", como Édipo, fura os olhos. Essa negação de suas forças talvez seja um prenúncio da degradação e consequente morte do Rei John Lennon, o que terá como resultado o caos que se instaura no reino visitado pelo corvo narrador.

Como se viu, o relato do corvo é ambíguo e, nesse sentido, permite que seja lido de outro modo, ou de um modo paralelo ao que foi lido até agora, como uma paródia livre do "Apocalipse", segundo o evangelho de João, que comparece no Novo Testamento. A paródia representa a intensificação de um processo de estilização, apoiando-se no efeito da descontinuidade ou na "intertextualidade das diferenças". ${ }^{13}$ Ela

11 “Conçu comme une projection d'un moi supérieur, un idéal à réaliser" (CHEVALIER; GHEERBRANT. Dictionnaire des symboles, p. 108, tradução nossa).

12 'L'établissement de la justice et de la paix, c'est-à-dire de l'équilibre et de l'harmonie du monde" (CHEVALIER; GHEERBRANT. Dictionnaire des symboles, p. 110, tradução nossa).

${ }^{13}$ HUTCHEON. Uma teoria da paródia, p. 28. 
necessita de um modelo que é submetido a uma operação transformadora de estrutura e, por consequência, de sentido, constituindo, assim, uma "repetição com distância crítica, que marca a diferença em vez da semelhança". ${ }^{14}$ Essa distância é atingida pela utilização da figura da ironia, que age sobre o princípio da duplicidade dos discursos ou pela deformação de um discurso em relação ao que lhe serve de modelo. $\mathrm{O}$ distanciamento irônico é que provoca a quebra com a tradição, com a ideia de continuidade, e instaura uma nova ordem, daí resultando na intenção crítica que tem como alvo, ora o próprio texto, que serve de ponto de partida; ora o contexto, dentro do qual o modelo é reatualizado; ora, ainda, em muitos casos, outros textos, frente aos quais, o modelo serve de espelho ou contraponto. É o que se verifica no texto de Prade: um modelo é recuperado para que se promova nele profundas modificações, visando à criação de uma nova ordem. Contudo, é preciso acentuar que o modelo - o "Apocalipse" de João - tem um sentido muito especial. Por ser resultado da visão de um profeta, que se comporta como intermediário entre Deus e os homens, acontece que sua linguagem é tão cifrada que se torna complicado (ou mesmo impossível) ao leigo decifrá-la. O efeito que se deseja provocar é mesmo o de espanto, o de choque, para que as palavras tenham peso suficiente para atemorizar o crente e levá-lo a tomar uma atitude, mesmo que ele não compreenda na totalidade o teor da mensagem.

A paródia acontece também no diálogo intertextual, quando o corvo reproduz, quase que literalmente, cenas, seres do modelo bíblico, deformando-as por meio do grotesco. A começar que, do mesmo modo que os anjos tocam trombetas para anunciar a nova no "Apocalipse", o pássaro negro chega à Ilha do Desterro com "a trombeta salvadora na garganta disforme". ${ }^{15}$ As sete cidades sobrevoadas pelo corvo equivalem às sete igrejas da Ásia, situadas em sete cidades - Éfeso, Esmirna, Pérgamo, Tiatira, Sardes, Filadélfia e Laodiceia -, que o profeta João visitou para divulgar as novas. Em alguns momentos, percebe-se o diálogo intertextual que o narrador estabelece com o texto do profeta bíblico, como nos seguintes versículos:

\footnotetext{
${ }^{14}$ HUTCHEON. Uma teoria da paródia, p. 17.

${ }^{15}$ PRADE. Relatos de um corvo sedutor, p. 13.
} 
2. E logo fui arrebatado em espírito, e eis que um trono estava posto no céu, e um assentado sobre o trono.

3. E o que estava assentado era, na aparência, semelhante à pedra de jaspe e de sardônica; e o arco celeste estava ao redor do trono e era semelhante à esmeralda.

[...]

6. E havia diante do trono um como mar de vidro, semelhante ao cristal, e, no meio do trono e ao redor do trono, quatro animais cheios de olhos por diante e por detrás.

7. E o primeiro animal era semelhante a um leão; e o segundo animal, semelhante a um bezerro; e tinha o terceiro animal o rosto como de homem; e o quarto animal era semelhante a uma águia voando.

[...]

9. E [...] os animais davam glória, e honra, e ações de graça ao que estava assentado sobre o trono, ao que vive para todo o sempre. [...]

11. Digno, és Senhor, de receber glória, e honra, e poder, porque tu criaste todas as coisas, e por tua vontade são e foram criadas. ${ }^{16}$

Em primeiro lugar, há a referência ao trono onde se senta o ungido, "o que vive para todo o sempre", que se parece a pedras preciosas. No texto do corvo, elas são dadas aos jovens que, tentados pelo poder da besta (na referência à paródia do número 666, que comparece, pela metade, como 333), formam gangues. Ainda é preciso apontar o "arco celeste" que circunda o trono do Escolhido, transformado no "arco-íris", preso ao dedo do pé de John Lennon. Na sequência, o "mar de vidro" do texto bíblico se transforma em "vidro estilhaçado" e as "sete lâmpadas de fogo", "os sete Espíritos de Deus", nas "lâmpadas de fogo brando". Também no relato do corvo comparecem os quatro animais bíblicos: o leão, o bezerro (o touro), e o terceiro animal com cara humana ("o cão persa com cara de homem”) e, por fim, a águia. O beatle configura-se, por conseguinte, como o Senhor, como o Deus Pai, adorado pelos animais simbólicos e transformado em Filho (o "Cordeiro", mencionado mais adiante no texto de João), para poder morrer e resgatar a humanidade pecadora.

Há outra passagem em que o nível paródico se torna bem mais patente. É quando acontece a referência ao "livro selado com sete selos",

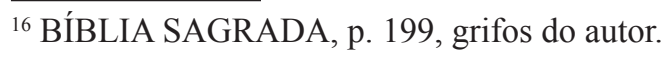


que "somente o Cordeiro é digno de abri[r]". Segundo João: “6. E olhei, e eis que estava no meio do trono e dos quatro animais viventes e entre os anciãos um Cordeiro, como havendo sido morto. 7. E veio e tomou o livro da destra do que estava assentado no trono". ${ }^{17}$

O Filho, o Cordeiro, recebe da mão direita do Pai, o livro da revelação, e é apenas ele que poderá abri-lo. No relato do corvo, há uma inversão paródica, porquanto o Cordeiro bíblico transmuda-se no "lobo esquizofrênico", que abre os lacres do livro da revelação com "suas garras atrofiadas". Um dócil animal, símbolo de pureza e de inocência, transmuda-se no seu oposto, num animal selvagem, indócil, lídimo representante desse novo mundo virado do avesso. $\mathrm{O}$ fato de ele se proclamar "pequeno príncipe do mundo" (numa referência clara à inocente personagem de Saint Exupéry, aliás, comparecendo na imagem dos céus cheios de relâmpagos, no primeiro parágrafo deste segundo relato) sugere um processo de identificação entre John Lennon/Deus, o rei do Apocalipse, montados sobre cavalos de cores diferentes e que espalhariam a discórdia na Terra. O primeiro dos animais é branco e quem se assenta sobre seu dorso "tinha um arco; e foi-lhe dada uma coroa, e saiu vitorioso para vencer"; o segundo é vermelho e a seu cavaleiro "foi-lhe dada uma espada", para que "tirasse a paz da terra", semeando a morte; o terceiro é negro e carrega uma balança na mão; o quarto é amarelo e tem como cavaleiro a Morte, que tem poder para "matar a quarta parte da terra com espada, e com fome, e com peste, e com as feras da terra". ${ }^{18}$ Quanto aos cavalos referidos pelo corvo, estão sem os cavaleiros e suas cores são "amarelo estridente", "azul transparente", "roxo em cima e marrom embaixo" e "cor de abóbora madura". A cor, em três deles, está associada a obras de pintores: o amarelo ao "girassol suicida de Van Gogh", o azul à fase azul de Picasso, o roxo e o marrom a Hyeronimus Bosch. Já o quarto, "bebedor de vodca e mascador de chicletes", diferencia-se por não estar associado a pintor algum e também por "criar obstáculos intransponíveis aos eventos adiante declinados". ${ }^{19}$ Talvez seja assim concebido por ser o último dos cavalos, representando a Morte.

$\mathrm{Na}$ sequência, surge a imagem do hermafrodita ("alegre hermafrodita estrangeiro" e "cordeiro andrógino"), um ser dual, ambíguo

\footnotetext{
${ }^{17}$ BÍBLIA SAGRADA, p. 201, grifos nossos.

${ }^{18}$ BÍBLIA SAGRADA, p. 200.

${ }^{19}$ PRADE. Relatos de um corvo sedutor, p. 14.
} 
como o corvo e os relatos, pois carrega em si os pares masculino/ feminino. Lembramos aqui do andrógino de Platão, "anjo apolíneo de distanciamento emocional e perfeição estética" ${ }^{20} \mathrm{O}$ hermafrodita vai agir sobre a realidade de modo similar ao corvo, promovendo um processo de transformação e/ou profanação de figuras e mitos: os "filósofos pré-socráticos" transformam-se em "escribas eruditos", os "quatro cavalos" do Apocalipse têm seu poder neutralizado, pois, "atraídos por ímãs gigantes", vão acabar no museu de Madame Tousseau. Outras modificações, sob instigação do andrógino, operam-se no mundo de magia: "larvas-serpentes" são soltas, uma toupeira chamada Kafka emerge do "centro da terra". Fechando o III relato, surge um "pistoleiro vidente" que se identifica ao "Cordeiro andrógino", a representação do Filho de Deus.

Outros dados paródicos surgem na continuidade do texto, entre eles, o dos sete anjos com sete trombetas, transformados, no relato, em "sete corvos bêbados", que se apresentam "por ordem de tamanho". O primeiro deles identifica-se como "Bachelard", o segundo, como "Lautréamont", o terceiro, como "Adolf", o quarto, como "Jack", o quinto, como o "Divino Marquês", o sexto, como "Rimbaud", e o sétimo, Buñuel. Chamamos a atenção aí para dois grandes grupos de seres especiais: o primeiro, formado por transformadores da realidade, a partir do imaginário: um pensador-filósofo-poeta (Bachelard), dois poetas (Rimbaud e Lautréamont), um prosador (Sade, o "Divino Marquês"), um cineasta (Buñuel); o segundo, por dois monstros assassinos (Hitler e Jack, o estripador). Em que pese à diferença de atuação na realidade, os membros dos dois grupos acabam se identificando, porque se salientam pelo excesso, a tal ponto que acabaram, com suas ações, por se constituir em figuras míticas e/ou verdadeiros arquétipos. Rimbaud, o poeta maldito, que morreu jovem na Abissínia, é um dos grandes precursores da literatura moderna, com sua poesia alucinada, nascida do delírio, responsável pela criação da cor das vogais. Lautréamont, pseudônimo de Isadore Ducasse, em Les chants de Maldoror, irmana-se a Sade, graças a seu gosto profanador, o que se verificará também no cinema iconoclasta de Buñuel. Pode-se dizer que todos eles pertencem ao Surrealismo, pelo gosto do nonsense, pela gratuidade das imagens, pela iconoclastia e, sobretudo, pela imaginação sem fios, que permite a livre associação de

${ }^{20}$ PAGLIA. Personas sexuais, p. 342. 
imagens, nascidas como que em estado bruto do inconsciente. Devido a isso tudo, torna-se patente porque foram convocados pelo corvo para representarem os anjos anunciadores dos novos tempos, contrapondo-se, assim, aos anjos bíblicos.

Esses artistas, "corvos bêbados", anjos exterminadores, que são conclamados neste Apocalipse parodiado, convergem não à toa para a figura de Bachelard, que, tratando dos elementos fundamentais da matéria - terra, ar, água, fogo -, soube privilegiar o devaneio, o onirismo: "Só um filósofo iconoclasta pode realizar esta pesada tarefa: para separar todos os sufixos de beleza, esforçar-se por encontrar, por trás das imagens que são mostradas, as imagens que se escondam, para ir até a própria raiz da força imaginativa." ${ }^{21}$

Ainda, segundo o pensador francês, o devaneio serve para "nos livrar do fardo da vida", ${ }^{22}$ transportando "o sonhador para um outro mundo", fazendo dele "um outro que não ele mesmo". ${ }^{23}$ É por isso que Bachelard lança "sobre os infelizes [...], com fervorosa compaixão, instantaneamente, água, fogo, terra e ar". ${ }^{24}$ Mas não só isso, pois o texto do corvo, também bachelardiano, é puro devaneio, no sentido de que a imaginação trabalha sobre a matéria, extraindo dela estados de espíritos, evocações, sensações. Ou ainda, "evoca um princípio de ordem espiritual que deforma a matriz reinventando o senso comum da vida, bem como a natureza". ${ }^{25}$

Nessa metamorfose, o ex-Cordeiro acompanha o drama dos penitentes, dentre os quais se salienta o saxofonista, enquanto a geografia da Ilha continua a ser enunciada: a Praia da Joaquina, o Costão do Santinho, o Cemitério da Paz, etc. É neste espaço real, transformado

21 "Seul un philosophe inconoclaste peut entreprendre cette lourde besogne: détacher tous les sufixes de la beauté, s'évertuer à trouver, derrière les images qui se montrent, les images qui se cachent, aller à la racine même de la force imaginante" (BACHELARD. L'eau et les rêves, p. 3, tradução nossa).

22 "Nous libérer des fardeaux de la vie" (BACHELARD. La poétique de la rêverie, p. 63 , tradução nossa).

23 "rêveur dans un autre monde", "un autre que lui-même". (BACHELARD. La poétique de la rêverie, p. 69, tradução nossa).

${ }^{24}$ PRADE. Relatos de um corvo sedutor, p. 16.

25 "evoca un principio d'ordine spirituale che deforma la matéria re-inventando il senso comune della vita, come anche la natura" (ANCONA. Frontieri dell'imaginario, p. 14, tradução nossa). 
em mítico, que a paródia do "Apocalipse" tem sua continuidade, com a apresentação da Besta e das pragas: "Prepararam-se contra a lubricidade da Besta, as acompanhantes chuvas de percevejos rançosos e outras pragas galopantes saídas das axilas que exalam pervertidos odores de intraduzível lembrança". ${ }^{26}$

Como o texto é paródico, funde o que no "Apocalipse" de João comparece separado; a aparição da Besta (ou melhor, das Bestas, já que, no texto de João, são duas, uma que vem do mar e outra, da terra) dá-se no capítulo 13, já o aparecimento das pragas (resumidas no texto do corvo a "percevejos rançosos e outras pragas galopantes") acontece nos capítulos 9, 15 e 16, com enorme variedade. Já o embate entre o dragão (contando como aliado a serpente, versículo 15) e a mulher - este representando o Mal, aquela, a mulher que há de gerar o filho de Deus (para redimir a Humanidade) e que comparece no capítulo 12 do "Apocalipse" - recebe também um tratamento multifacetado no relato do corvo, pois o animal mítico transmuda-se em "dragoa faminta, grávida" e a serpente é a "serpente emplumada", cujo efeito negativo está em devorar "a luz no início do parto". Mas não acontece tão-só uma metamorfose do dragãodemônio, femininizando-se - na realidade, no jogo de ambiguidades do texto, o que há é um processo de fusão entre o tentador e a redentora, pois a "dragoa faminta" é "grávida", cuja "cauda brilhante" está prestes a esvaziar "a arca da aliança de ancestral ferrugem". Os aspectos do Bem e do Mal fundem-se, na gravidez da dragoa (a preparar a vinda do Escolhido), uma representação do Bem, e na referência da serpente "que devora a luz no início do parto", uma representação do Mal.

No VI relato, verifica-se a reconstrução paródica da Babilônia, a que João se refere nos capítulos 18 e 19 do seu “Apocalipse”. Chamamos a atenção para o seguinte aspecto: entre os grandes pecados que assolam a fabulosa cidade, destacam-se os da lubricidade e os da riqueza que, em realidade, estão interligados. As imagens do pecado da luxúria amontoam-se no caos do relato - "a mulher calva pendurada no pescoço [...] sobre o seu libidinoso macho", "a lésbica invejosa e de formação aristotélico-tomista", decepando "a cabeça do inesperado filho", "Saturno emasculado", a "prostituta de New Orleans", "Bebel, a filha caçula da meretriz", "puta militante". ${ }^{27}$ Essas imagens todas, ligadas à sexualidade

${ }^{26}$ PRADE. Relatos de um corvo sedutor, p. 30.

${ }^{27}$ PRADE. Relatos de um corvo sedutor, p. 27. 
ou à negação dela, convergem para o instante em que os habitantes da cidade maldita (a "tribo anã, herética somente à noite") assumem de maneira deliberada o pecado, ao sacrificarem "sem remorso" o "cordeiroagrimensor”, seduzidos que são pelo número da Besta, 666.

No relato de número IX, entra uma nova personagem que é a representação de Cristo - o "peregrino" que "havia chegado, envolto por uma vestimenta inconsútil, carregando pesada cruz de marfim no ombro". ${ }^{28}$ O peregrino/canibal, desdobramento paródico de Cristo, purga a Ilha e, devorado pelos corvos, tem um destino similar ao de Prometeu. Depois de enfrentado o Apocalipse e a passagem devastadora do canibal, a "Ilha, iluminada ou não, é riquíssimo esplendor dos esplendores das raízes destas memórias voláteis". O Juízo Final, como resultado do Apocalipse, serve para absolver "os transgressores [...] no tempo dos aflitos" ${ }^{29}$ A representação simbólica que fecha toda a narrativa, anunciada pelo corvo sedutor, "o único eleito pelos deuses para comunicar isso", devido a suas qualidades especiais, tem um sentido muito claro: purga a terra dos pecados, de todo o mal, por meio de uma ação transgressora, em que o sagrado e o profano trocam de posições e em que as figuras santificadas recebem novas roupagens ou são submetidas a um processo contínuo de metamorfoses, como se verificou na figura do Cordeiro, por exemplo.

A sedução do corvo dá-se pelo encantamento que seu relato exerce tanto sobre os ouvintes dispersos pelos locais que sobrevoa, quanto sobre o receptor do texto narrativo. Mas os sentidos dados à palavra "sedutor" que mais chamam a atenção na narrativa são: "o que desencaminha, que desvia, afasta do caminho" e "o que exerce sedução; atraente encantador". A sedução do corvo exerce-se, numa primeira instância, para envolver, conquistar, atrair. Isso acontece por intermédio da linguagem e da narrativa onírico-erótica que servem ao devaneio e que encantam o receptor do texto ou narratário.

No entanto, é preciso considerar ainda que esse encantamento, pela sensação de liberdade que provoca, pode conduzir a uma postura de total desprendimento em relação à vida, às obrigações do cotidiano. Søren Kierkegaard, em Diários de um sedutor, compreende o sedutor como um esteta, como aquele que não quer comprometimento de forma

${ }^{28}$ PRADE. Relatos de um corvo sedutor, p. 51.

${ }^{29}$ PRADE. Relatos de um corvo sedutor, p. 58. 
alguma, por isso vive de gozo em gozo, sempre tentando preencher um vazio existencial persistente. Esse seria o modo de vida estético, de acordo com o pensamento do filósofo dinamarquês, "caracterizado pelo hedonismo romântico e sofisticado, ao qual se contrapõe, não apenas a dor, mas, sobretudo, o tédio". ${ }^{30}$ Esses relatos, de certo modo, cumprem o mesmo desiderato, libertando, com seu discurso requintado, suas imagens poderosas, seu onirismo, seu erotismo delirante, o homem da realidade estúpida e tediosa. O corvo, com sua lábia, seu poder de persuação, sua sedução, torna o leitor mais livre, permite-lhe voar nas asas da fantasia e penetrar num mundo regido por suas próprias leis, onde vêm aportar os seres históricos e imaginários que se interpenetram numa fábula primordial. O corvo, enfim, é um corruptor, pois, ao profanar, ao criar um discurso subversivo, desvia o homem de seu caminho, de sua rotina banal, abrindo-lhe o abismo das perversões. Mas não é isso que se exige de toda grande literatura? Seduzir, perverter, desencaminhar, desorientar...

\section{Referências}

ANCONA, Franzina. Frontieri dell'imaginario: mito e rito nella scrittura di Péricles Prade. Palermo: Ítalo-Latino-Americana Palma, 1987.

BACHELARD, Gaston. La poétique de la rêverie. Paris: PUF, 1971.

BACHELARD, Gaston. L'eau et les rêves. Paris: José Corti, 1973.

BAKHTIN, Mikhail. Problemas da poética de Dostoievski. Rio de Janeiro: Forense Universitária, 2002.

BÍBLIA SAGRADA. Tradução de João Ferreira de Almeida. São Paulo: Sociedade Bíblica do Brasil, 1995.

CHEVALIER, Jean; GHEERBRANT, Alain. Dictionnaire des symboles. Paris: Seghers, 1973. 4 v.

CIRLOT, Juan Eduardo. A Dictionary of Symbols. New York: Philosophical Library, 1983.

HUTCHEON, Linda. Uma teoria da paródia. Lisboa: Edições 70, 1985.

KIERKEGAARD, Søren. Diários de um sedutor. São Paulo: Abril, 1979.

${ }^{30}$ KIERKEGAARD. Diários de um sedutor, p. 47. 
MOISÉS, Massaud. Dicionário de termos literários. ed. rev. amp. São Paulo: Cultrix, 2004.

PAGLIA, Camille. Personas sexuais: arte e decadência de Nefertite a Emily Dickinson. Tradução de Marcos Santarrita. São Paulo: Companhia das Letras, 1992.

PRADE, Péricles. Relatos de um corvo sedutor. Florianópolis: Letras Contemporâneas, 2008. 